\title{
LA PROTECCIÓN DE LOS DERECHOS FUNDAMENTALES DE LA POBLACIÓN MIGRANTE INTERNACIONAL POR LA CORTE CONSTITUCIONAL COLOMBIANA *
}

\section{The protection of the fundamental rights of the international migrant population by the Colombian Constitutional Court}

\author{
Diana Fernández Mejía** \\ Erika van Arcken Salas***
}

Recepción: 25/10/2019. Aceptado: 27/12/2019

DOI: http://dx.doi.org/10.21017/Rev.Repub.2020.v28.a82

\section{RESUMEN}

Este artículo de investigación tiene como propósito analizar las sentencias de tutela de la Corte Constitucional Colombiana, por medio de las cuales se han protegido los derechos fundamentales de la población migrante internacional, con el fin de identificar y comprender las reglas que el Alto Tribunal Constitucional ha fijado en la materia.

Palabras clave: Migrantes internacionales; Derechos Fundamentales; Sentencias de Tutela.

* Artículo producto del proyecto de investigación Perspectivas de análisis de los derechos económicos, sociales y culturales: dinámicas del desarraigo en Hispanoamérica, durante el período 2015-2018, del Grupo de Investigación Problemas Contemporáneos del Derecho y la Política de la Universidad de San Buenaventura Cali.

** Abogada de la Universidad Santiago de Cali. Magíster en Derechos Humanos y Democratización de la Universidad Externado de Colombia en convenio con la Universidad Carlos III de Madrid. Doctoranda en Derecho de la Universidad Sergio Arboleda. Profesora Investigadora de la Universidad de San Buenaventura Cali. Miembro del Grupo de Investigación Problemas Contemporáneos del Derecho y la Política. Correo electrónico: difeme@usbcali.edu.co.

*** Abogada de la Universidad Santiago de Cali. Especialista en Derecho Administrativo de la Universidad Libre Seccional Cali. Magíster en Derecho Constitucional de la misma Universidad. Doctoranda de la Universidad de Buenos Aires (Argentina). Profesora Investigadora de la Universidad de San Buenaventura Cali. Miembro del Grupo de Investigación Problemas Contemporáneos del Derecho y la Política. Correo electrónico: evarcken@usbcali.edu.co. 


\begin{abstract}
The main purpose of this research paper is to analyze guardinship actions of the Colombian Constitutional Court, through which the fundamental rights of the international migrant population has been protected, in order to identify and understand the rules that the High Constitutional Court has set up in the matter.
\end{abstract}

Key words: Migrants, Constitutional Rights, Judgments (tutela).

\title{
INTRODUCCIÓN
}

La Comisión Interamericana de Derechos Humanos (2016), ha definido la movilidad internacional como aquella situación que "implica el cruce de una persona o grupo de personas de una frontera estatal internacionalmente reconocida de su país de origen, con el propósito de establecerse por un periodo de tiempo o de manera permanente en otro país del cual no es nacional". Dicho fenómeno puede obedecer a múltiples causas que lleven a una persona de manera voluntaria o forzada a migrar, bien sea porque su vida, integridad personal o libertad se encuentran amenazadas. Sin embargo, la propia Comisión Interamericana señala que otras razones que impactan en la migración internacional obedece a aspectos de índole económica, social, política o ambiental, entre los que se encuentran situaciones de violencia generada por actores estatales y no estatales, los conflictos armados, la desigualdad, la pobreza, la falta de garantía de derechos económicos, sociales y culturales, la inestabilidad política, la corrupción, así como la inseguridad, diversas formas de discriminación, desastres naturales y el impacto del cambio climático (CIDH, Informe de Movilidad Humana, 2016, p. 11).

Por lo anterior, los Estados en ejercicio de su soberanía estatal han adoptado diferentes normas dirigidas a controlar el fenómeno migratorio. El Estado colombiano no ha sido ajeno a adoptar políticas y leyes dirigidas a regular las condiciones de ingreso, permanencia y expulsión de los extranjeros, lo que significa que ha fijado su propia política migratoria. De manera específica, la Corte Constitucional colombiana se ha encargado de aprobar diferentes sentencias por medio de las cuales ha protegido los derechos fundamentales de los migrantes internacionales que han solicitado la tutela de sus derechos y libertades fundamentales, derechos que el Alto Tribunal ha considerado que deben ser respetados y garantizados a partir de las obligaciones internacionales que ha asumido el Estado colombiano. Conforme a lo expuesto, el presente artículo tiene como objetivo realizar un análisis de los fallos de tutela proferidos por la Corte Constitucional colombiana, por medio de los cuales se han 
salvaguardado los derechos fundamentales de las personas migrantes internacionales que han acudido a la acción de tutela para lograr la protección de sus derechos.

Este artículo constituye un avance del Proyecto de Investigación "Perspectivas de análisis de los derechos económicos, sociales y culturales: dinámicas del desarraigo en Hispanoamérica, durante el período 2015-2018", particularmente de su objetivo específico consistente en estudiar los criterios argumentativos de los operadores judiciales que fundamentan el desarrollo de sus decisiones en materia de protección de los derechos fundamentales de los migrantes internacionales.

Como parte del desarrollo del mencionado objetivo específico, se ha agotado como primer punto un estudio de los fundamentos que ha adoptado la Corte Constitucional Colombiana en sede de tutela, específicamente frente al caso de migrantes internacionales. Los resultados de este punto son los que se exponen en el presente escrito, en el que se muestra un análisis de las sentencias de tutela emitidas entre los años 2013 y 2019, por medio de las cuales la Corte Constitucional ha protegido los derechos fundamentales de la población migrante internacional en Colombia. Para cumplir con este propósito en primer lugar se presentan aquellos fallos donde se han protegido derechos civiles, como son el derecho al debido proceso, la personalidad jurídica, la nacionalidad y el estado civil; posteriormente, se exponen las sentencias por medio de las cuales la Corte ha protegido derechos como la unidad familiar, los derechos de los niños y el derecho a la salud, reconocidos en el texto de la Constitución como derechos económicos sociales y culturales; y se finaliza con un análisis de los criterios argumentativos adoptados por el Alto Tribunal Constitucional.

\section{PROBLEMA DE INVESTIGACIÓN}

Colombia desde su primera época republicana mostró un interés por promover la inmigración internacional, tildándola como una de las bases para la prosperidad y grandeza del país, esto puede verse consignado en la Ley 13 del 11 de junio de 1823, en la que se estableció fomentar eficazmente la inmigración de extranjeros europeos y norteamericanos. Pese a ese interés de adoptar medidas para incentivar la llegada de inmigrantes durante los siglos XIX y XX, en Colombia no se logró una gran corriente de inmigrantes en las mismas proporciones como se llegó a presentar en otros países del continente americano (Mejía Ochoa, W., 2012, pp. 186 y 187).

Entre los años sesenta y noventa Colombia se caracterizó por ser un país con una mayor cantidad de personas emigrantes que inmigrantes, esto se debió a 
múltiples causas, entre ellas los problemas de desigualdad socieconómica que incidieron en el mercado laboral, como también por la percepción de inseguridad ocasionada por el conflicto interno armado. Según el documento "Extranjeros en Colombia: 2005-2016"1 el censo general realizado en el año 2005 reflejó que el número de colombianos en el exterior en ese momento era de 3.378.345, y en el año 2012 se estimó aproximadamente 4.700 .000 según el Ministerio de Relaciones Exteriores, siendo los principales destinos Estados Unidos, España, Venezuela, Ecuador y Canadá (p. 6). La situación se muestra diferente con relación a los inmigrantes en Colombia, puesto que, de acuerdo con el censo del año 2005, el número de extranjeros para ese entonces era de 109.971, y en el año 2010 el Banco Mundial estimó esta cifra en 110.297 (Extranjeros en Colombia: 2005-2016, p. 6).

El panorama de migrantes internacionales en Colombia ha cambiado significativamente a partir del año 2014 debido a la creciente migración de venezolanos hacia Colombia. Según explicación de María Rocío Bedoya Bedoya, el éxodo de venezolanos hacia Colombia se ha dado lentamente distinguiéndose tres oleadas durante las últimas dos décadas, la primera consistió en la llegada de empresarios atraídos por la globalización económica, como fueron los dueños de Alimentos Polar, Congrupo y Farmatodo; la segunda fue la emigración de ejecutivos de alto nivel que trabajaban en la compañía petrolera Pdvsa, con ocasión de la llegada al poder de Hugo Chávez quien decidió destinar parte de su renta a la financiación de proyectos sociales de su gobierno; la tercera oleada se distingue como una de los mayores emigraciones venezolanas a partir del año 2014, debido a la crisis económica, social y política que se vive en ese país (Bedoya Bedoya, 2019, p. 132).

La cifra exacta de venezolanos en territorio colombiano es un dato complejo de definir "teniendo en cuenta que las fronteras son espacios vivos y que cualquier labor de registro migratoria, por juiciosa que sea, no resulta exhaustiva" (Castro Franco, 2019, p. 18). Teniendo esto presente, Migración Colombia para el 30 de agosto de 2018, reportó la presencia de 953.593 venezolanos en territorio colombiano (República, 2018, como se cita en Castro Franco, 2019, p. 18). Ante este fenómeno el Estado colombiano, institucionalmente dispuso transitoriamente de medidas con el propósito de formalizar a la población venezolana con estatus de irregular, como por ejemplo otorgándoles permisos especiales de permanencia (PEP), para que pudieran trabajar formalmente y acceder a servicios de salud y educación. Otras medidas adoptadas por el Gobierno consistieron en "suspender la Tarjeta de Movilidad Fronteriza (TMF) para ciudadanos venezolanos, crear el Grupo Especial Migratorio (GEM) coordinado por el Gerente de Frontera del Gobierno Nacional (...) También se resolvió modificar el sistema de visado a través de la Resolución 6045 del 02 de agosto de 2017" (Bedoya Bedoya, 2019, p. 139). 
El Estado también actúa a través de su Rama Judicial, quien tiene la responsabilidad de administrar justicia en los conflictos bajo su conocimiento. Hace parte de esta Rama la jurisdicción constitucional, que tiene el propósito de velar por la protección de los derechos fundamentales de todas las personas que se encuentran en el territorio colombiano, como también de custodiar la supremacía de la Constitución, estando a la cabeza de ésta jurisdicción la Corte Constitucional, a quién se le ha conferido la guarda de la integridad y supremacía de la Constitución. Teniendo en cuenta el contexto del fenómeno migratorio últimamente vivido por Colombia y la labor de la jurisdicción constitucional, se hace necesario formular el siguiente problema de investigación el cual se condensa en la siguiente pregunta: ¿qué criterios argumentativos ha empleado la Corte Constitucional en sus sentencias de tutela para la protección de los derechos fundamentales de los migrantes internacionales en Colombia?

\section{ESTRATEGIA METODOLÓGICA}

Para el cumplimiento del objetivo propuesto se utilizó el enfoque metodológico de investigación cualitativo haciendo uso de un método hermenéutico encaminado a descubrir en las sentencias de tutela de la Corte Constitucional colombiana, el grado de protección de los derechos fundamentales de migrantes internacionales. El modelo de investigación usado para el estudio de las jurisprudencias es sistematización y lege data (descriptiva), propuesto por Virgilio Latorre (2012), ya que el propósito de esta investigación es realizar un análisis jurídico interpretativo y descriptivo de las sentencias en mención.

Para la elección de las sentencias se tuvo en cuenta que fueran sólo de tutela emitidas por el Alto Tribunal Constitucional de Colombia y que se relacionaran con una materia, la exigencia de la protección de derechos fundamentales de migrantes internacionales. Para el análisis de las providencias se realizó una descripción sucinta de los hechos, se identificó el planteamiento de los problemas jurídicos resueltos por la Corte en estas sentencias, se analizó las ratio decidendi que ayudaron a resolver dichos problemas, se extrajeron de las reglas jurisprudenciales las decisiones frente a la protección de los derechos fundamentales.

\section{RESULTADOS}

\section{Derecho al debido proceso}

El derecho al debido proceso de los migrantes ha sido objeto de protección por parte de la Corte Constitucional, situación que se evidencia en la sen- 
tencia T-956 de 2013, la cual constituye uno de los primeros fallos donde la Corte tuvo la oportunidad de pronunciarse respecto al derecho fundamental al debido proceso. Los hechos de la decisión judicial se enmarcan en la orden de deportación de un migrante irregular de nacionalidad china, quien tiene su familia en Colombia, conformada por su compañera permanente y su hija menor de edad, de nacionalidad colombiana. Si bien es cierto, el problema jurídico que resolvió el fallo consistió en establecer si existió violación del derecho de la niña a tener una familia y a no ser separada de ella, en razón a la orden de deportación de su padre, la sentencia también analizó los cargos relacionados con la violación al debido proceso, debido a que en el procedimiento administrativo migratorio que culminó con la orden de deportación, el ciudadano chino no contó con la asistencia de un intérprete que le permitiera comprender los hechos y normas que motivaron dicha sanción.

En esta ocasión, la Corte Constitucional consideró que el derecho al debido proceso es un derecho fundamental del cual gozan también los extranjeros, tal como lo estipula el artículo 100 de la Constitución Política (C.P.). Para explicar el alcance de este derecho, la Corte acudió a diferentes instrumentos internacionales como fueron el Pacto Internacional de Derechos Civiles y Políticos y la Convención Americana de Derechos Humanos, y a su vez, entró en diálogo con el Comité de Derechos Humanos y la Corte Interamericana de Derechos Humanos, quienes se han referido a la obligación que tiene el Estado de garantizar en condiciones de igualdad y sin discriminación alguna, el derecho al debido proceso de los migrantes, independiente de su estatus migratorio. Así las cosas, la Corte consideró que el debido proceso implica las garantías judiciales de contradicción y defensa, las cuales se refieren en palabras del tribunal, “a que la persona concernida en un proceso judicial o administrativo debe tener a su disposición instancias materiales e idóneas para conocer las razones que dan lugar al trámite, las pruebas en que se sustentan, así como los argumentos jurídicos y de hecho que fundan el actuar del juez o la autoridad administrativa" (Corte Constitucional, Sentencia T956 de 2013).

El Alto Tribunal también manifestó que la garantía judicial de contradicción y defensa exige la remoción de todas las barreras jurídicas y fácticas que impidan el ejercicio efectivo de tales derechos, entre las que se encuentra el desconocimiento del idioma en que se adelanta un trámite judicial o administrativo. Por ende, en la sentencia objeto de análisis, la Corte Constitucional concluyó que el no haberle permitido al ciudadano chino contar con un intérprete durante el procedimiento administrativo migratorio, le causó la vulneración de su derecho fundamental al debido proceso, toda vez que el ciudadano no pudo expresarse, comprender los supuestos fácticos y jurídi- 
cos de la decisión de la autoridad migratoria y oponerse a la decisión relacionada con su deportación.

Con base en lo expuesto, la Corte Constitucional ordenó a la autoridad competente (Migración Colombia), reiniciar la actuación administrativa de carácter migratorio frente al ciudadano chino, bajo el cumplimiento estricto de las condiciones propias del debido proceso, incluyendo la provisión de un intérprete del idioma chino mandarín en cada una de las etapas del trámite.

Un caso similar al descrito anteriormente, está representado en la sentencia T295 de 2018 cuyos hechos narran que el señor Makoto Odakura ingresó al país y se le otorgó un permiso de ingreso y permanencia en calidad de turista por 90 días. Sin embargo, cuando el señor Makoto acudió al Grupo de Control Migratorio Especializado Regional Aeropuerto El Dorado con el fin de resolver su situación migratoria, el tiempo de su permanencia ya había vencido. Ante esta situación, la autoridad competente inició y agotó las etapas de la actuación administrativa sancionatoria ese mismo día y adoptó la medida de deportación en contra del señor Odakura, sin que este contara con el servicio de intérprete y/o traductor oficial (Corte Constitucional, Sentencia T-295 de 2018).

En la anterior sentencia, la Corte tuvo la oportunidad de referirse específicamente a un problema jurídico relacionado con el derecho al debido proceso. Así las cosas, el problema jurídico planteado por el tribunal constitucional fue el siguiente:

\begin{abstract}
¿Migración Colombia vulneró el derecho fundamental al debido proceso del ciudadano japonés Makoto Odakura en el procedimiento administrativo migratorio de carácter sancionatorio que se surtió el 12 de abril de 2017, al no suministrarle el servicio de intérprete y/o traductor oficial y llevar a cabo el procedimiento administrativo sancionatorio de carácter migratorio en un término inferior a una hora? (Corte Constitucional, Sentencia T-295 de 2018).
\end{abstract}

En consecuencia, la Corte Constitucional planteó que el derecho al debido proceso debe aplicarse a toda clase de actuaciones judiciales y administrativas, el cual supone entre otras garantías judiciales, el derecho de contradicción y defensa, el derecho a ser oído y la garantía de que el proceso se lleve a cabo dentro de un plazo razonable.

Las otras consideraciones expuestas por la Corte en la sentencia objeto de análisis, fueron las mismas que utilizó en la sentencia T-956 de 2013, lo que significa que la Corte reiteró que los migrantes son sujetos de especial pro- 
tección en razón a la situación de indefensión en la que se encuentran, lo cual "se deriva del desconocimiento de la forma en que opera el sistema jurídico local, el idioma, la ausencia de lazos familiares y comunitarios, entre otros, como también que los migrantes en situación de irregularidad son un grupo vulnerable". Asimismo, la Corte Constitucional interpretó el alcance del derecho al debido proceso a la luz de lo dispuesto en el artículo 8.2.a del Pacto de San José y a lo establecido por la Corte Interamericana como intérprete autorizada de dicho tratado, comprendiendo que el debido proceso implica el derecho que le asiste a toda persona de ser asistida gratuitamente por un traductor o intérprete en todo tipo de actuación, bien sea ésta judicial o administrativa.

Para la Corte, al señor Odakura se le violó su debido proceso al no haberle suministrado el servicio de un intérprete y/o traductor, y por haber llevado a cabo un procedimiento en un tiempo tan corto que no le haya permitido al nacional japonés, ejercer sus derechos a la defensa y a la contradicción.

De lo anterior, se puede evidenciar que una regla jurisprudencial sostenida por la Corte en relación con la garantía del derecho al debido proceso de los migrantes, es el deber que tiene el Estado de proveer un traductor en caso que el migrante no domine el idioma castellano. Asimismo, otra regla jurisprudencial que se detecta en la sentencia T-295 de 2018 es que si bien, el Estado tiene la potestad de fijar políticas migratorias en virtud del ejercicio de su soberanía, esto no significa que esté habilitado para desplegar actuaciones arbitrarias que terminen menoscabando derechos fundamentales como es el debido proceso.

A lo anterior, se suma que la Corte Constitucional también consideró que se violó la garantía judicial del plazo razonable debido a que el procedimiento administrativo fue resuelto el mismo día en un tiempo aproximado de una hora, lo que ocasionó que se afectara la eficacia de los recursos internos disponibles para controvertir la decisión de la autoridad estatal (Corte Constitucional, Sentencia T-295 de 2018).

Continuando con la identificación de los casos en los cuales la Corte Constitucional ha protegido el derecho al debido proceso, nos encontramos con la sentencia T-241 de 2018 por medio de la cual se acumuló la revisión de siete (7) expedientes de tutela, entre los cuales seis (6) acciones se promovieron en contra de la Registraduría Delegada de Barranquilla y una (1) contra la Registraduría Delegada de Santa Fe de Antioquia, ante la negativa de éstas de tramitar el registro civil extemporáneo de nacimiento de hijos de padres colombianos nacidos en Venezuela, por no aportar el acta de nacimiento debidamente apostillado por el país vecino. Los actores presentaron las accio- 
nes en nombre propio o en representación de sus hijos menores de edad, manifestaron ser nacionales venezolanos y tener al menos uno de sus padres con nacionalidad colombiana, por lo que consideraron tener derecho al reconocimiento de su derecho a la nacionalidad. Agregaron que ante la situación humanitaria y política que afronta Venezuela no les ha sido posible cumplir con la formalidad de apostillar el acta de nacimiento, por lo que solicitaron que se les permitiera acreditar este requisito con la presentación del testimonio de dos personas.

Bajo esos presupuestos fácticos, la Corte Constitucional en la Sentencia T-241 de 2018 se vio enfrentada a resolver el siguiente problema jurídico:
¿Vulneró la Registraduría Nacional del Estado Civil, a través de sus delegadas la Registraduría Especial Distrital de Barranquilla y la Registraduría Especial de Santa Fe de Antioquia, los derechos de los accionantes al debido proceso (...), al exigir un requisito legal para la expedición extemporánea del regis- tro civil, como es la apostilla de las actas de nacimiento de ciudadanos nacidos en Venezuela con padres colombianos, y no permitir suplir este requisito con la declaración de dos (2) testigos como lo ha señalado la jurisprudencia constitucional?

Finalmente, para la Corte Constitucional, el requisito de apostillar las actas de nacimiento y no permitir la acreditación del nacimiento por medio de dos (2) testigos es excesivo, desproporcionado y sobrepone lo formal sobre lo sustancial. En consonancia con lo anterior, el tribunal constitucional propuso como regla que el exceso de formalidad en las actuaciones administrativas representa una violación al debido proceso. En palabras de la Corte:

\begin{abstract}
(...) deviene en una trasgresión al debido proceso de las personas dado que en los casos bajo estudio implica una carga desproporcionada en el ámbito probatorio, ante la posibilidad de suplir el requisito con otro igualmente contemplado en la ley. Esto es una cuestión que concierne al debido proceso y de forma directa impacta en el derecho a la nacionalidad, cuyo reconocimiento, como se ha venido indicando, no depende de la prueba del nacimiento como tal (con apostille o con testigos), sino del cumplimiento de todos los requisitos de ley que se acrediten ante la autoridad registral (Corte Constitucional, Sentencia T-241 de 2018).
\end{abstract}

\title{
Derecho a la Nacionalidad y a la Personalidad Jurídica
}

En la mencionada sentencia T-241 de 2018 objeto de estudio en el ítem sobre el derecho al debido proceso, cuyos hechos se relacionan con la exigencia formal por parte de las Registradurías Delegadas de Barranquilla y Santa Fe de Antioquia 
de apostillar actas de nacimiento e impedir suplir este requisito con la presentación del testimonio de dos personas para tramitar el registro civil extemporáneo de nacimiento de hijos de padres colombianos nacidos en Venezuela, el problema jurídico que resolvió la Corte Constitucional relacionado con el tema objeto de análisis, se construye de la siguiente forma: ¿Vulnera la Registraduría Especial Distrital de Barranquilla y la Registraduría Especial de Santa Fe de Antioquia, los derechos de los accionantes a la personalidad jurídica, nacionalidad y al estado civil, al exigir la apostilla de las actas de nacimiento de ciudadanos nacidos en Venezuela con padres colombianos como requisito legal para la expedición extemporánea del registro civil, y no permitir sustituir este requerimiento con la declaración de dos testigos?

Las razones de decisión que respondieron a este problema jurídico se basaron en el estudio por parte de la Corte Constitucional del derecho a la personalidad jurídica y los atributos de la personalidad como son la nacionalidad y el estado civil, pues estos son "elementos esenciales de la condición humana en el Estado Social de Derecho" (Corte Constitucional, C-241 de 2018).

Expuso la Corte Constitucional que la personalidad jurídica es el "medio por el cual se reconoce la existencia a la persona humana dentro del ordenamiento jurídico", la cual se encuentra reconocida por normas materialmente constitucionales como lo son el artículo 14 de la C.P. ${ }^{2}$, el 16 del Pacto Internacional de Derechos Civiles y Políticos (PIDCP $)^{3}$ y el $3^{\circ}$ de la Convención Americana sobre Derechos Humanos (CADH $)^{4}$. Agregó que la personalidad jurídica es un derecho fundamental, que es el presupuesto que permite el reconocimiento y efectividad de los derechos y garantías consignados en la Constitución y su materialización implica los atributos de la persona humana.

Los atributos de la personalidad por su parte, son una categoría autónoma del derecho civil cuyo objetivo es relacionar la personalidad jurídica con el ordenamiento jurídico. Los atributos son seis: el estado civil, la nacionalidad, el nombre, la capacidad, el patrimonio y el domicilio. Estas características están

1 Texto elaborado por el Grupo de Estudios Institucionales sobre Migración de Migración Colombia en colaboración con la Coordinación de Proyecciones de Población y Análisis Demográfico - DANE, y con las Direcciones Regionales Amazonas, Oriente, y Nariño, así como las Subdirecciones de Control Migratorio, Extranjería y Verificaciones Migratorias.

2 El artículo 14 de la C.P., establece que: “Toda persona tiene derecho al reconocimiento de su personalidad jurídica".

3 El artículo 16 del PIDCP, consagra que: "Todo ser humano tiene derecho, en todas partes, al reconocimiento de su personalidad jurídica".

$4 \mathrm{El}$ artículo $3^{\circ}$ de la $\mathrm{CADH}$, dispone que: “Toda persona tiene derecho al reconocimiento de su personalidad jurídica". 
inherentes al ser humano y a través de ellas se efectiviza el derecho a la personalidad jurídica, como también los derechos políticos. Como se indicó, entre los atributos de la personalidad se encuentra la nacionalidad, el cual es reconocido como un derecho fundamental autónomo consignado en el artículo 96 de la C.P., en el que se definen los requisitos generales para el reconocimiento en Colombia de la nacionalidad por nacimiento y por adopción.

Sobre este derecho fundamental a la nacionalidad, la Corte Constitucional resaltó las siguientes reglas jurisprudenciales comprendidas en las siguientes sentencias:

\begin{tabular}{|c|l|}
\hline Sentencia & \multicolumn{1}{c|}{ Regla jurisprudencial } \\
\hline Sentencia C-893 de 2009 & $\begin{array}{l}\text { La nacionalidad es el vínculo jurídico que une a una persona con el } \\
\text { Estado, es un derecho con tres dimensiones: "el derecho a adquirir una } \\
\text { nacionalidad, a no ser privado de ella y a cambiarla". }\end{array}$ \\
\hline Sentencia C-622 de 2013 & $\begin{array}{l}\text { Ese vínculo legal que es la nacionalidad significa la existencia jurídica del } \\
\text { individuo y el disfrute de derechos (fundamentales, económicos, sociales } \\
\text { y culturales), y la delimitación de obligaciones (sociales, políticas y } \\
\text { económicas), tanto del Estado como la persona nacional. }\end{array}$ \\
\hline Sentencia C-451 de 2015 & $\begin{array}{l}\text { El reconocimiento de la nacionalidad hace que el "individuo adquiera y } \\
\text { ejerza los derechos y responsabilidades inherentes a la pertenencia a una } \\
\text { comunidad política". }\end{array}$ \\
\hline
\end{tabular}

Otro atributo de la personalidad es el estado civil que es también un derecho fundamental a través del cual se hacen efectivos otros derechos como la nacionalidad, el nombre, el voto, entre otros. Su carácter como derecho constitucional se lo da su vínculo directo con la personalidad jurídica, pues a partir del estado civil las personas demuestran: "(i) su existencia a través del registro civil de nacimiento; (ii) su relacionamiento familiar, mediante los datos de filiación real y del registro civil de matrimonio; y (iii) la extinción de la vida, con el registro civil de defunción" (Corte Constitucional, T-241 de 2018).

Teniendo en cuenta las anteriores claridades conceptuales definidas por la Corte Constitucional sobre personalidad jurídica y los atributos de la personalidad como son la nacionalidad y el estado civil, para el estudio del caso objeto de acción este Alto Tribunal encontró que los actores pretenden hacer efectivas estas prerrogativas logrando el reconocimiento del derecho consignado en el artículo 96 de la C.P., específicamente en el literal b) del numeral $1^{\circ}$, en el que se reconocen como nacionales colombianos a "[l]os hijos de padre o madre colombianos que hubieren nacido en tierra extranjera y fuego se domiciliaren en territorio colombiano o registraren en una oficina consular de la República".

Para la consecución de lo anterior, la Corte Constitucional aclaró que el Decreto 356 de 2017 es el que reglamenta el trámite para la inscripción extemporánea 
de nacimiento en el registro civil ante el funcionario registral o consular, el cual en su artículo 2.2.6.12.3.1., relaciona que la documentación que debe acompañar la solicitud debe ser la siguiente:

(i) declaración bajo la gravedad de juramento de que la inscripción no se haya realizado previamente; (ii) certificado de nacido vivo y en el caso de haber nacido en el extranjero, se requiere "el registro civil de nacimiento expedido en el exterior debidamente apostillado y traducido"; y (iii) las partidas religiosas cuando corresponda. (Corte Constitucional, C-241 de 2018)

Resaltó además la Corte que dicha norma también establece una regla excepcional que consiste que de no poder acreditarse el nacimiento con los documentos anteriores, deberán presentar una solicitud en donde se consigne todos los datos personales de quien requiere el registro y "deberá acudir con al menos dos (2) testigos hábiles quienes prestarán declaración bajo juramento mediante la cual manifiesten haber presenciado, asistido o tenido noticia directa y fidedigna del nacimiento del solicitante" (Decreto 356 de 2017).

En virtud de lo expuesto, la regla jurisprudencial de la Corte Constitucional que resolvió el problema jurídico exalta primero el carácter fundamental del derecho a la personalidad jurídica que permite a los seres humanos ser parte de las relaciones que se despliegan en el tráfico jurídico. Este derecho fundamental adquiere un alcance mayor gracias a los atributos de la personalidad que "son esenciales para el desarrollo de la personalidad humana, ya que otorgan a las personas la individualidad e identidad que se predica de su capacidad jurídica y de las relaciones individuales y familiares que desarrollan" (Corte Constitucional, T-241 de 2018), también permiten el desarrollo de otros derechos fundamentales tanto civiles como políticos (por ejemplo el voto, acceso a servicios subsidiados de salud y educación), por lo que su negación afecta de manera directa el goce de otros derechos fundamentales. Por lo anterior, para la Corte Constitucional la exigencia de requisitos de manera desproporcionada como es el de aportar el acta de nacimiento debidamente apostillado por las autoridades de un país con las situaciones particulares políticas y humanitarias como las de Venezuela, vulneran los derechos fundamentales de la personalidad jurídica y los atributos de la personalidad como la nacionalidad y el estado civil, y más cuando las mismas normas colombianas otorgan una solución excepcional como lo es la presentación de dos testigos.

De acuerdo con las razones argumentadas por la Corte Constitucional, esta concluyó que las Registradurías Delegadas incurrieron en un abuso de forma como es la exigencia de la apostillada y no permitir otra alternativa también legal como poder acreditar el nacimiento a través de dos testigos, vulnerando de esta forma los derechos fundamentales de los accionantes, por consiguiente 
resolvió ampararles el derecho a la nacionalidad, al estado civil y a la personalidad jurídica y ordenarles que acepten como prueba del nacimiento de estos los dos (2) testigos para suplir el requisito de apostilla.

\section{Derecho a la unidad familiar y derechos de los niños}

La Corte Constitucional mediante la sentencia T-338 de 2015 estudió un caso de agencia oficiosa tácita, en el que el señor Xinghua Huang, a pesar de no manifestar que interpuso acción de tutela en nombre de su progenitora, la señora Yinzhen Zhou, por los relatos de los hechos consignados en el escrito de tutela se deduce que lo hizo en nombre de ella, quien al momento de presentar la acción se encontraba en el Ecuador y no tenía visa para permanecer en territorio colombiano. En los hechos se alegó la vulneración de los derechos fundamentales "a la familia como núcleo principal de la sociedad y protección de las personas de la tercera edad", por parte de la Unidad Administrativa Especial Migración Colombia del Ministerio de Relaciones Exteriores de Colombia quien le negó el otorgamiento de la visa como beneficiaria a la señora Yinzhen Zhou de nacionalidad china, con el argumento de tener "condición de irregular".

De los hechos se destaca que el accionante era ciudadano chino con visa de residente colombiana desde el año 2013, que sus padres eran de la tercera edad y no tenían parientes en la República China. Ante la situación relatada se indicó que su padre ingresó a Colombia el 20 de febrero de 2014 logrando tener la visa en calidad de beneficiario, sin embargo no sucedió lo mismo con su madre, ya que esta ingresó de manera irregular al Estado colombiano, omitiendo el control migratorio, pues primero llegó al Ecuador para entrar al territorio colombiano sin visa y/o sin el sello de ingreso, desconociendo en su momento lo consignado en los artículos 19 y 20 del Decreto 834 de $2013^{5}$. Esta vulneración de las normas colombianas le acarreó una sanción económica y la negación en dos ocasiones de la visa en calidad de beneficiaria por el Ministerio de Relaciones Exteriores.

El problema jurídico que resolvió en este caso la Corte Constitucional se encuadró en la siguiente pregunta: ¿El Ministerio de Relaciones Exteriores vulneró los derechos fundamentales de la señora Yinzhen Zhou (...) a la unidad familiar, al negarle la visa como beneficiaria porque infringió las normas migratorias al permanecer en forma irregular en el país? Para responder este problema jurídico y de acuerdo con el tema que ocupa nuestra atención, el Alto Tribunal Constitucional estudió dos ejes temáticos: la protección a la familia y los derechos de los migrantes.

5 En este decreto se establecían disposiciones en materia migratoria de la República de Colombia. 
Para la protección de la familia, la Corte consideró importante resaltar su concepto desde la interpretación que ha hecho de esta teniendo en cuenta la realidad social, como también su ámbito de amparo jurídico. En ese sentido, el concepto de familia "no incluye tan solo la comunidad natural compuesta por padres, hermanos y parientes cercanos, sino que se amplía incorporando aun a personas no vinculadas por los lazos de la consanguinidad" (Corte Constitucional, C-577 de 2011), que tienen el propósito de construir una unidad de vida o destino fundada en el respeto, amor y solidaridad. Por consiguiente, su protección no está reducida sólo al tipo de familias que surgen del matrimonio o de las uniones maritales de hecho, este ámbito de amparo se extiende a las familias formadas por parejas del mismo sexo o las monoparentales, "teniendo en cuenta que el concepto de familia no puede ser entendido de manera aislada, sino en concordancia con el principio del pluralismo" (Corte Constitucional, C-278 de 2014).

La familia tiene un ámbito de protección en el articulado de la Constitución y en varios instrumentos internacionales sobre derechos humanos que prevalecen en el orden interno por ser ratificados por el Estado colombiano, esto en virtud del bloque de constitucionalidad 6 . La piedra angular en el marco de la Constitución que ampara la familia se encuentra en el artículo $5^{\circ}$, que como principio fundamental dispone que el Estado "ampara la familia como institución básica de la sociedad", igualmente en el artículo 42, que la posiciona como el núcleo fundamental de la sociedad y establece la garantía de su protección integral, asegurando su honra, dignidad e intimidad y propendiendo por el respeto recíproco y el trato igualitario entre sus integrantes.

6 Las normas internacionales que relaciona la Corte Constitucional son:

["E]l protocolo adicional a los convenios de Ginebra del 12 de agosto de 1949 (protocolo II), suscrito en Ginebra el 8 de junio de 1977; Convención Internacional sobre la Protección de los Derechos de todos los Trabajadores Migratorios y de sus Familiares, suscrita en Nueva York el 18 de diciembre de 1990; Convención sobre la Prevención y el Castigo de Delitos contra personas internacionalmente protegidas, inclusive los Agentes Diplomáticos, suscrita en Nueva York el 14 de diciembre de 1973; Convención Internacional para prevenir, sancionar y erradicar la violencia contra la mujer, suscrita en la ciudad de Belem Do Para, Brasil el 9 de junio de 1994; Convenio relativo a la protección del niño y a la cooperación en materia de adopción internacional, suscrito en La Haya el 29 de mayo de 1993; Protocolo Adicional a la Convención Americana sobre Derechos Humanos en Materia de Derechos Económicos, Sociales y Culturales «Protocolo de San Salvador», suscrito en San Salvador el 17 de noviembre de 1988; Convención Interamericana sobre Obligaciones Alimentarias, hecha en Montevideo el 15 de julio de 1989; Acuerdo sobre asistencia a la niñez entre la República de Colombia y la República de Chile, hecho en Bogotá, D. C., el 16 de julio de 1991; y el Protocolo Facultativo de la Convención sobre los Derechos del Niño relativo a la venta de niños, la prostitución infantil y la utilización de los niños en la pornografía, adoptado en Nueva York, el 25 de mayo de 2000, entre otros. (Corte Constitucional, T-338 de 2015). 
Por otro lado, en lo que respecta a los derechos de los migrantes, la Corte Constitucional subrayó que el artículo 100 de la C.P. reconoce a los extranjeros los mismos derechos civiles y garantías que gozan los nacionales, pero la Constitución y la ley pueden establecer limitaciones para el disfrute de los mismos. Agregó que los extranjeros, al igual que los nacionales, están en el deber de acatar la Constitución y las leyes, y respetar y obedecer a las autoridades, de acuerdo a lo consignado en el artículo $4^{\circ}$ de la C.P. En lo que respecta a la garantía de los derechos extranjeros que se encuentren de manera irregular en el país, destacó que esa misma corporación en Sentencia T-321 de 2005, concluyó que por ninguna razón las autoridades administrativas pueden ignorar la vigencia y alcance de sus derechos fundamentales o los inherentes a la persona humana, garantizados en la Constitución Política y en Tratados Internacionales.

En lo que respecta a la protección del derecho fundamental a la unidad familiar, trajo a colación las razones de decisión consignadas en las Sentencias T215 de 1996 y T-956 de 2013, las cuales se sintetizan de la siguiente forma:

\begin{tabular}{|c|c|}
\hline \multirow{3}{*}{ Sentencia T-215 de 1996} & $\begin{array}{l}\text { Hechos relevantes: Se estudia el caso de un ciudadano alemán con } \\
\text { compañera e hijas menores de edad todas de nacionalidad colombiana. } \\
\text { Con ocasión a su estancia de manera irregular en Colombia, fue } \\
\text { deportado y sancionado con la prohibición de ingresar al territorio } \\
\text { colombiano por el término de un año. }\end{array}$ \\
\hline & $\begin{array}{l}\text { Razón de decisión: La Corte en esa ocasión arguye que el Estado y sus } \\
\text { autoridades no pueden afectar la unidad o continuidad de la familia } \\
\text { "salvo que exista fundamento legal concreto como es el ejercicio de los } \\
\text { poderes punitivos o correccionales". Sin embargo, resalta que cuando una } \\
\text { autoridad pública realice un acto propio de sus funciones soportado } \\
\text { jurídicamente, este acto no debe sacrificar el núcleo esencial de los } \\
\text { derechos fundamentales, "mucho más cuando existe una cláusula } \\
\text { constitucional de prevalencia de derechos como la que impone el artículo } \\
44 \text { de la Carta Política". }\end{array}$ \\
\hline & $\begin{array}{l}\text { Decisión: La Corte resuelve los derechos fundamentales y suspende de } \\
\text { manera transitoria la orden deportación para que resolviera "sin } \\
\text { dilaciones y sin sanciones, su legal estancia y permanencia en el territorio } \\
\text { de la República y atendiera sus deberes familiares". }\end{array}$ \\
\hline \multirow{3}{*}{ Sentencia T-956 de 2013} & $\begin{array}{l}\text { Hechos relevantes: La Corte conoció el caso de un ciudadano de } \\
\text { nacionalidad china con esposa residente en Colombia y con una hija } \\
\text { menor de edad nacida en este país. Por encontrarse de manera irregular } \\
\text { en el Estado colombiano le impuso una multa y se le expidió orden de } \\
\text { deportación. Su esposa presenta acción de tutela en representación de la } \\
\text { hija en común. }\end{array}$ \\
\hline & $\begin{array}{l}\text { Razón de decisión: Con relación a la unidad familiar, la Corte exaltó la } \\
\text { importancia de la existencia del entorno familiar para el adecuado } \\
\text { desarrollo de los niños y para la materialización de sus derechos } \\
\text { fundamentales, requiriendo que estos cuenten con una familia para la } \\
\text { satisfacción de sus necesidades físicas, materiales y afectivas. }\end{array}$ \\
\hline & $\begin{array}{l}\text { Decisión: Se protegió el derecho fundamental a tener una familia y a no } \\
\text { separarse de ella. }\end{array}$ \\
\hline
\end{tabular}

Fuente: elaboración propia a partir de la información de la Sentencia T-388 de 2015. 
La regla jurisprudencial que estableció la Corte Constitucional para resolver el problema jurídico planteado dispone en primer lugar que el Estado colombiano está en la obligación de respetar el ejercicio y goce de los derechos fundamentales de los migrantes, de la misma forma como garantiza los derechos de los nacionales, independientemente de su estatus migratorio ("regular" o "irregular"). Específicamente en lo que tiene que ver con la garantía del derecho fundamental de la unidad familiar, manifestó este Tribunal Constitucional que en los procedimientos de carácter administrativo y judicial, es deber fundamental de las autoridades del Estado tratar que sus actuaciones no causen un daño irreparable del derecho fundamental a la unidad y continuidad de la familia, procurando siempre respetar cuando menos su núcleo esencial.

De acuerdo con lo expuesto la decisión prohijada por la Corte Constitucional consistió en conceder la protección del derecho fundamental a la unidad familiar de la señora Yinzhen Zhou, aclarando que con ella no se invade las competencias que corresponden al Gobierno Nacional y tampoco está señalando que la actuación de la Cancillería Colombiana es contraria a la ley cuando le ha negado la visa en calidad de beneficiaria, sino que su intervención en esta ocasión como juez constitucional se soportó en la necesidad de moderar las actuaciones de la administración con la intención de que en estas también se garanticen derechos humanos, como es el derecho fundamental de la unidad familiar de una extranjera que no tiene más familia que la que reside en Colombia.

Es importante destacar que dentro de la ratio decidendi de la sentencia objeto de estudio, se hizo énfasis en las sentencias T-215 de 1996 y T-956 de 2013 cuyo problema jurídico se centró en determinar si con la vulneración del derecho a la unidad familiar, se violaban los derechos de los niños y niñas, ante lo cual la Corte Constitucional consideró que la separación de un menor de edad de su núcleo familiar como puede ocurrir en los casos de deportación, no sólo constituye una violación del derecho a la familia sino a los derechos de los niños y niñas.

\section{Derecho a la Salud}

En la sentencia T-074 de 2019 se relata que el accionante, el señor César Armando Torres Suaréz, en calidad de agente oficioso de su esposa Daniela Dayari Origuen Hernández, instauró acción de tutela en contra de la Secretaría de Salud Departamental de Risaralda, la Secretaría de Salud Municipal de Pereira, la Secretaría de Gobierno de Pereira -Oficina Emigrante- y Migración Colombia, al considerar que estos le vulneraron a su esposa los derechos fundamentales a la salud y seguridad social con motivo de los siguientes hechos relevantes: plantea que su esposa y él son nacionales venezolanos que tomaron la decisión 
en el mes de septiembre de 2017 de venir a Colombia radicándose municipio de Pereira (Risaralda). Expuso que con motivo del estado de embarazo de su esposa acudieron a diferentes entidades estatales prestadoras del servicio de salud para que le brindaran las valoraciones y tratamientos necesarios, sin embargo, no recibió por parte de éstas respuesta positiva, porque su pareja no cuenta con la documentación requerida para lograr la respectiva atención.

Frente a lo anterior, el problema jurídico que en esta oportunidad resolvió la Corte Constitucional se enmarcó en la siguiente pregunta: ¿los accionados vulneraron los derechos fundamentales a la salud y a la seguridad social de Daniela Dayari Origuen Hernández, al no prestarle los servicios de salud que requiere por su estado de embarazo con el argumento de no tener regularizada su situación migratoria y tampoco cumplir con los requisitos para acceder a los servicios de salud? Para resolver este problema jurídico la Corte Constitucional abordó principalmente los siguientes tres temas: de manera general estudió lo relacionado con el reconocimiento de los derechos de los extranjeros en Colombia, luego se concentró específicamente en la procedencia de la garantía del derecho a la salud de los migrantes en Colombia y finalmente describió el requisito que deben agotar los migrantes venezolanos para lograr su afiliación ante el Sistema General de Seguridad Social (SGSSS).

Con relación a los derechos que disfrutan los extranjeros en Colombia, el Alto Tribunal Constitucional destacó que de conformidad con el artículo 100 de la C.P., estos gozan de los mismos derechos civiles que se les reconocen a los colombianos pero que el legislador podrá "por razones de orden público, subordinar a condiciones especiales o negar el ejercicio de determinados derechos civiles a los extranjeros". También destaca de este mismo artículo, que en su inciso segundo dispone que los extranjeros poseen en el territorio colombiano las mismas garantías concedidas a los nacionales "salvo las limitaciones que establezcan la Constitución o la ley". La interpretación que la Corte Constitucional le ha dado a este artículo, leído de forma sistemática con los artículos $2^{\circ}$ de la Declaración Universal de los Derechos Humanos ${ }^{7}$ y el artículo 24 de la Convención Americana de Derechos Humanos ${ }^{8}$, es que en Colombia los extranjeros en principio gozan de los mismos derechos fundamentales y garantías que tienen los nacionales colombianos ${ }^{9}$, porque son inherentes a la

7 Especialmente cuando se indica que "toda persona tiene todos los derechos y libertades proclamados en esta Declaración, sin distinción alguna de raza, color, sexo, idioma, religión, opinión política o de cualquier otra índole, origen nacional o social, posición económica, nacimiento o cualquier otra condición".

8 Cuando establece que "todas las personas son iguales ante la ley. En consecuencia, tienen derecho, sin discriminación, a igual protección de la ley".

9 Esta misma interpretación ha sido desarrollada por la Corte Constitucional en sentencias tales como la T-215 de 1996 y T-316 de 2016. 
persona, pero para su ejercicio deben acatar lo consagrado en Constitución y las leyes tal y como lo establece el artículo $4^{\circ}$ de la Norma Superior.

Con relación al derecho a la salud de los migrantes en Colombia, recalcó la Corte Constitucional que conforme a lo consignado en la Observación General No. 14 del Comité de Derechos Económicos, Sociales y Culturales, los países no pueden emitir políticas que produzcan actos de discriminación relacionados con la salud y las necesidades de la mujer, teniendo por ende el deber de garantizar los servicios de salud de todas las personas en su dimensión preventiva, curativa y paliativa, cubriendo inclusive a los solicitantes de asilo y migrantes irregulares. En virtud de lo anterior, dijo la Corte que Colombia a través de la Ley 1751 de 2015 en sus artículos 10 y 14, dispuso que cualquier persona que se encuentre en el territorio, sea nacional o extranjero, tiene derecho a recibir atención de urgencias de manera oportuna, sin exigencia de pago o autorización administrativa alguna, no pudiendo las entidades correspondientes negarse a brindar lo requerido argumentando las exigencias en mención. La atención de urgencias además de estabilizar los signos vitales, se orienta a:

[P]reservar la vida y prevenir las consecuencias críticas, permanentes o futuras, mediante el uso de tecnologías en salud para la atención de usuarios que presenten alteración de la integridad física, funcional o mental, por cualquier causa y con cualquier grado de severidad que comprometan su vida o funcionalidad. (Resolución No. 5269, 2017)

Frente al requisito que deben agotar los migrantes venezolanos para lograr su afiliación ante el SGSSS, advirtió la Corte Constitucional que estos deben primero regularizar su situación por lo menos a través del Permiso Especial de Permanencia $(\mathrm{PEP})^{10}$, que les concede a los venezolanos permiso para permanecer de manera regular en el país hasta por dos años, esta exigencia es en consideración a que al igual que los demás residentes del país, el reconocimiento de derechos suscita la obligación de cumplir con las normas colombianas ${ }^{11}$.

10 Este permiso fue creado por la Resolución No. 5797 de 2017 del Ministerio de Relaciones Exteriores, para aquellos venezolanos que reunieran los requisitos consignados en su artículo $1^{\circ}$ :

1. Encontrarse en el territorio colombiano a la fecha de publicación de la presente resolución.

2. Haber ingresado al territorio nacional por Puesto de Control Migratorio habilitado con pasaporte.

3. No tener antecedentes judiciales a nivel nacional e internacional.

4. No tener una medida de expulsión o deportación vigente.

11 Frente a esta posición el Alto Tribunal Constitucional invita a revisar las siguientes sentencias: T-316 de 2016, T-705 de 2017 y T-210 de 2018. 
La regla jurisprudencial que estableció la Corte Constitucional para resolver el problema jurídico planteado se concretiza de la siguiente manera: los extranjeros al igual que los nacionales gozan en Colombia de los mismos derechos civiles, teniendo a su vez, la obligación ambos de acatar la Constitución y las leyes, y de respetar y obedecer a las autoridades. En virtud de lo anterior, frente al derecho a la salud, los migrantes internacionales regulares o irregulares, cuentan con el derecho de recibir atención básica de urgencias en el territorio, sin que sea legítimo que se establezcan obstáculos para ello, sin embargo, si lo que pretende el extranjero es una atención médica integral, en cumplimiento de los deberes definidos por la ley, deben regularizar su situación migratoria pues es un requisitos para lograr la afiliación al SGSSS.

La decisión adoptada en este caso por la Corte Constitucional, fue declarar la carencia actual del objeto por constituirse un hecho superado, ya que logró evidenciar que la ESE Salud Pereira le ofreció los servicios médicos que necesitaba la agenciada y del que estaba por nacer, cumpliendo con ello con las obligaciones constitucionales y legales de ofrecerle una atención en salud de carácter urgente por su condición de embarazo, para preservar de manera digna la vida de la madre y del que está por nacer pese a no estar regularizada su situación migratoria en Colombia.

Una de las primeras sentencias de tutela emitidas por la Corte Constitucional en la que concedió el amparo del derecho fundamental a la salud a migrantes, es la T-210 de 2018. La particularidad de lo resuelto en esta providencia consistió en que el Alto Tribunal decidió revisar dos expedientes de tutela que coinciden en lo siguiente: 1 . Los afectados son dos nacionales venezolanos, la primera es una mujer de 34 años de edad con una enfermedad catastrófica (cáncer de cuello uterino), y el segundo un menor de 2 años de edad que desde su nacimiento padecía de una hernia inguinal y escrotal. 2. En ambos casos los médicos tratantes les ordenaron tratamiento y procedimiento médico con carácter de urgente (radioterapia y quimioterapia para la primera, y cirugía pediátrica para el segundo), los cuales fueron negados por accionados (Hospital Universitario Erasmo Meoz y el Instituto Departamental de Salud de Norte de Santander). 3. Los jueces de instancia (el de única en el primero y de segunda instancia en el caso del menor), decidieron no tutelar el derecho fundamental a la salud de los afectados porque no contaban con documentos válidos que demostraran la legalización de su permanencia en Colombia y que les permitiera realizar su afiliación al SGSSS.

Uno de los problemas jurídicos que resolvió la Corte Constitucional consistió en determinar si “ ¿el Hospital Universitario Erasmo Meoz y el Instituto 
Departamental de Salud de Norte de Santander vulneraron los derechos a (...) la salud, a la vida y a la integridad física de los accionantes al negarse a autorizar y prestar los servicios médicos que éstos solicitaron?". Para resolver este cuestionamiento, la Corte entre sus razones decisión abordó el derecho de los migrantes en materia de salud en Colombia, en el que concluyó que si bien es cierto que de acuerdo a lo consignado en el artículo 100 de la C.P., hay un mandato expreso de igualdad entre nacionales y extranjeros, también lo es que dicho artículo autoriza "la posibilidad de desarrollar un tratamiento diferenciado en relación con los nacionales", pero siempre que existan suficientes razones que justifiquen dicho tratamiento.

Aunque arguye la Corte que algo que sí está establecido en igualdad de proporciones tanto para nacionales como para extranjeros, es el deber de "acatar la Constitución y las leyes, y respetar y obedecer a las autoridades" tal y como lo define el artículo $4^{\circ}$ de la C.P. En virtud de esta prescripción constitucional la vinculación de los extranjeros al SGSSS “(...) está sujeta, en principio, a que los mismos cumplan con los requisitos legales contemplados en las normas que regulan el trámite de afiliación al SGSSS, de la misma manera en que le corresponde hacerlo a los nacionales".

No obstante lo anterior en materia de Derechos Económicos, Sociales y Culturales (DESC), dejó claro también el Alto Tribunal Constitucional, destacando lo advertido en sentencia C-843 de 2007, que:

(...) toda persona, incluyendo a los extranjeros, tienen derecho a recibir una atención mínima del Estado en casos de extrema necesidad y urgencia, en aras de atender sus necesidades primarias y respetar su dignidad humana; un núcleo esencial mínimo que el Legislador no puede restringir, especialmente en materia de salud. (Corte Constitucional, C-210 de 2018)

De acuerdo con lo expuesto, al ser los servicios médicos ordenados a los accionantes con carácter de urgente, les concedió a estos la protección de sus derechos fundamentales a la salud y vida digna.

\section{Análisis de la tendencia de la Corte Constitucional para a la protección de los derechos fundamentales de los migrantes internacionales}

En el escrito se destaca el precedente judicial consignado en seis sentencias de tutela emitidas por la Corte Constitucional, en las que esta corporación estudia la protección de derechos fundamentales de migrantes internacionales que se encuentran en territorio colombiano, tales como el debido proceso (sentencias T-956 de 2013 y T-295 de 2018), la nacionalidad y la personalidad jurídica (sentencia T-241 de 2018), la unidad familiar y derechos de los niños 
(sentencia T-338 de 2015), y el derecho a la salud (sentencias T-210 de 2018 y T-074 de 2019).

La tendencia de la Corte Constitucional para la protección de los derechos fundamentales de los migrantes internacionales parte de la interpretación que este tribunal realiza del artículo 100 de la Constitución Política, en el que se establece que los extranjeros en Colombia disfrutan de los mismos derechos civiles que se les otorgan a los nacionales colombianos, haciendo la salvedad que por razones de orden público, la ley podrá "subordinar a condiciones especiales o negar el ejercicio de determinados derechos civiles". Este mismo artículo agrega que los extranjeros gozarán de las mismas garantías que tienen los colombiano, exceptuándose aquellas que están consignadas en la Constitución y la ley. Este artículo es estudiado de manera concordante con el principio fundamental consignado en el artículo $4^{\circ}$ de la Constitución, en el que además de exaltar la supremacía de la norma fundamental, establece que tanto nacionales como extranjeros en Colombia tienen el deber de acatar la Constitución y las leyes, como también respetar y atender a las autoridades del Estado.

Teniendo como base estas normas materialmente constitucionales y como quiera que en Colombia toda persona, nacional y extranjera, puede acudir a la garantía de la acción de tutela para la protección de sus derechos fundamentales según el artículo 86 de la Constitución, la Corte Constitucional en su calidad de guarda e intérprete oficial de la norma superior ha marcado precedente judicial, en el que se ha establecido unas reglas que definen la forma de satisfacción y garantía de los derechos de los migrantes en Colombia. En ese sentido se encuentra que frente a los casos que han sido revisados por dicha corporación en los que se discute la vulneración de los derechos fundamentales al debido proceso, a la nacionalidad, personalidad jurídica, a la unidad familiar y los derechos de los niños, la tendencia ha sido mucho más garantista que cuando el derecho en discusión es la salud, esto se refleja en las reglas destacadas en el análisis de las sentencias objeto de estudio las cuales se repasan a continuación.

Las reglas jurisprudenciales definidas para el reconocimiento y protección del debido proceso identificadas en las sentencias T-956 de 2013 y T-295 de 2018, establecen que los migrantes en Colombia son considerados sujetos de especial protección, esto porque pueden estar frente a situaciones como el desconocimiento de la forma como funcional el sistema jurídico nacional, el desconocimiento del idioma, la falta de vínculos familiares y comunitarios, entre otros, encontrándose en situación de indefensión lo que los hace un grupo vulnerable. Por lo anterior, otra regla que se define es que en todo proceso judicial y administrativo en el que esté incurso un migrante se le debe propor- 
cionar todas las herramientas que le permitan comprender las razones de hecho y derecho que lo llevaron a ser parte de estos procesos, como es tener la asistencia de un intérprete o traductor, así tendrá la oportunidad de ejercer plenamente de sus derechos a la contradicción y defensa, propios de un debido proceso.

Con relación al reconocimiento y protección de los derechos a la nacionalidad y la personalidad jurídica, es importante precisar que el caso consignado en la sentencia T-241 de 2018, muestra la dificultad que han tenido venezolanos con padres colombianos, para lograr formalizar el reconocimiento extemporáneo de su nacionalidad como colombianos en virtud de los consignado en el literal a) del numeral $1^{\circ}$ del artículo 96 de la Constitución. En esta ocasión la Corte Constitucional exalta que la exigencia de manera desproporcionada de requisitos como es el de aportar el acta de nacimiento debidamente apostillada por las autoridades de un país con las situaciones particulares políticas y humanitarias como las de Venezuela, vulneran los derechos fundamentales de la personalidad jurídica y los atributos de la personalidad como la nacionalidad y el estado civil, y más si las mismas formas internas ofrecen soluciones excepcionales como la de los testigos para de esta forma materializar los derechos afrentados.

Para la garantía de los derechos a la unidad familiar y de los niños, el Alto Tribunal Constitucional en la sentencia T-338 de 2015, ha propendido porque en ciertos casos como por ejemplo en los que estén implicados personas de la tercera edad y menores de edad, sean morigeradas las reglas migratorias con el propósito de conservar la vigencia de garantías superiores como es el respeto por los derechos fundamentales. Por tal motivo argumenta que en los procedimientos de carácter administrativo y judicial, es deber fundamental de las autoridades del Estado tratar que sus actuaciones no causen un daño irreparable derechos fundamentales, procurando siempre respetar cuando menos su núcleo esencial.

Finalmente frente a la protección al derecho a la salud, la Corte Constitucional no manifiesta entre sus argumentos que los migrantes sean considerados como sujetos de especial protección que se encuentran en estado de indefensión siendo por esta razón un grupo vulnerable, sino que destaca que en virtud de los consagrado en el artículo $4^{\circ}$ y 100 de la Constitución Política, los extranjeros al igual que los nacionales gozan en Colombia de los mismos derechos civiles, teniendo a su vez, la obligación ambos de acatar la Constitución y las leyes, y de respetar y obedecer a las autoridades. En virtud de lo anterior, frente al derecho a la salud, los migrantes internacionales regulares o irregulares, cuentan con el derecho de recibir atención básica de urgencias en el territorio, sin que sea legítimo que se establezcan obstáculos para ello, sin embargo, si lo que 
pretende el extranjero es una atención médica integral, en cumplimiento de los deberes definidos por la ley, deben regularizar su situación migratoria pues es un requisitos para lograr la afiliación al SGSSS.

\section{CONCLUSIONES}

Del análisis realizado a las sentencias de tutela seleccionadas, se concluye que en Colombia por mandato constitucional consignado en el artículo 100, los extranjeros gozan de los mismos derechos civiles que se le otorgan a los nacionales, sin embargo advierte esta misma norma que, por razones de orden público la ley puede "subordinar a condiciones especiales o negar el ejercicio de determinados derechos civiles a los extranjeros". Esta disposición también señala que los extranjeros disfrutan de las mismas garantías concedida a los nacionales, "salvo las limitaciones que establezcan la Constitución o la ley". Lo anterior significa, de acuerdo a interpretación realizada por la Corte, que la Carta está expresamente consintiendo un trato diferenciado de los extranjeros en relación con los nacionales, siempre y cuando existan suficientes razones que respalden esas diferenciaciones.

En aquellos casos en los que se ha protegido los derechos fundamentales debido proceso, a la nacionalidad, personalidad jurídica, a la unidad familiar y los derechos de los niños, la tendencia de la Corte Constitucional ha sido mucho más proteccionista que cuando el derecho en discusión es la salud, también catalogado como prestacional, pues ha advertido este tribunal que si bien es cierto el Estado tiene la potestad de fijar políticas migratorias en virtud del ejercicio de su soberanía que de alguna forma limitan derechos civiles de extranjeros en "condición irregular" en el país, también lo es que, esto no significa que esté habilitado para desplegar actuaciones arbitrarias que terminen menoscabando derechos fundamentales, dándoles un tratamiento de sujetos de especial protección ya sea por el desconocimiento que pueden llegar a tener del sistema jurídico nacional, del idioma, por la ausencia de vínculos familiares y comunitarios, siendo un grupo vulnerable en situación de indefensión.

Por su parte cuando el derecho en discusión es la salud, la Corte Constitucional ha señalado que el reconocimiento de derechos a los extranjeros les genera de manera concomitante el deber de cumplir y respetar la Constitución y las leyes colombianas, de acuerdo a lo establecido en el artículo $4^{\circ}$ de la C.P. En virtud de lo anterior, pudo encontrarse cómo el Alto Tribunal Constitucional en los casos relacionados con la salud, verificaba el cumplimiento de los deberes constitucionales y legales por parte de los extranjeros para finalmente decidir si otorgar o no el amparo constitucional. Sin embargo, la ley también 
permite que los migrantes internacionales regulares o irregulares, gozen del derecho a recibir atención básica de urgencias en el territorio sin ningún tipo de obstáculos.

\section{REFERENCIAS}

Bedoya Bodoya, M. R. (2019). Factores que influyen en el éxodo exacerbado de población venezolana hacia Colombia del 2015 al 2018. En Jeffrey H. Cohen \& Paulette K. Schuster (Eds.), Modelando el Transnacionalismo. Londres, Reino Unido: Transnational Press London.

Castro Franco, A. (Ed.). (2019). Venezuela migra: aspectos sensibles del éxodo hacia Colombia. Temas de Derecho Internacional Publico N.2. Bogotá, Colombia: Universidad Externado de Colombia.

Latorre, V., (2012). Bases metodológicas de la investigación jurídica. Valencia, España: Tirant lo Blanch.

Mejía Ochoa, W. (2012). Colombia y las Migraciones Internacionales. Evolución reciente y panorama actual a partir de las cifras. Revista Interdisciplinar da Mobilidade Humana. No. 39, pp. 185-210. Recuperado de http:// www.scielo.br/pdf/remhu/ v20n39/v20n39a10

Unidad Administrativa Especial Migración Colombia. Extranjeros en Colombia: 20052016. Aproximación migratoria a sus trayectorias en Colombia. Recuperado de https:/ /www.migracioncolombia.gov.co/documentos/estadisticas/publicaciones/ Extranjeros\%20en $\% 20$ Colombia $\% 20$ Aproximacion $\% 20$ migratoria $\% 20 \mathrm{a} \% 20$ sus $\%$ 20trayectorias\%20en\%20Co.pdf

\section{REFERENCIAS NORMATIVAS}

Asamblea General de la ONU, (1948). Declaración Universal de los Derechos Humanos. Resolución 217 A (III), Paris. Recuperado de https://www.un.org/en/universal-declaration-human-rights/

Convención Americana sobre Derechos Humanos (1978). San José, Costa Rica. Recuperado de https://www.oas.org/dil/esp/tratados_B-32_Convencion_Americana _sobre_Derechos_Humanos.htm

Asamblea General de la ONU, (1976). Pacto Internacional de Derechos Civiles y Políticos (PIDCP). Resolución 2200 A (XXI). Recuperado de https:/ / www.ohchr.org/ $\mathrm{sp} /$ professionalinterest/pages/ccpr.aspx 
Comité de Derechos Económicos, Sociales y Culturales de las Naciones Unidas (2000). Observación General No. 14. Ginegra. Recuperado de https:/ / www.acnur.org/ fileadmin/Documentos/BDL/2001/1451.pdf

Congreso de la República de Colombia. (16 de febrero de 2015). Por medio de la cual se regula el derecho fundamental a la salud. Ley 1751 de 2015. D.O. 49.427

Presidencia de la República, Ministerio de Relaciones Exteriores. (24 de abril de 2013). Por el cual se establecen disposiciones en materia migratoria de la República de Colombia. Decrero 834 de 2013.

Presidencia de la República, Ministerio del Interior. (3 de marzo de 2017). Decreto Único Reglamentario del Sector Justicia y del Derecho. Decrero 356 de 2017.

Ministerio de Salud y Protección Social. (22 de diciembre de 2017). Por la cual se actualiza integralmente el Plan de Beneficios en salud con cargo a la Unidad de Pago por Capitación (UPC). Resolución No. 5269 de 2017.

Ministerio de Relaciones Exteriores. (25 de julio de 2017). Por medio de la cual se crea un Permiso Especial de Permanencia. Resolución No. 5797 de 2017

\section{REFERENCIAS DE SENTENCIAS}

Corte Constitucional colombiana. (15 de mayo de 1996) Sentencia T-215. M.P. Fabio Moron Díaz.

Corte Constitucional colombiana. (4 de abril de 2005) Sentencia T-321. M.P. Humberto Antonio Sierra Porto.

Corte Constitucional colombiana. (2 de diciembre de 2009) Sentencia C-893. M.P. Mauricio González Cuervo.

Corte Constitucional colombiana. (26 de julio de 2011) Sentencia T-577. M.P. Gabriel Eduardo Mendoza Martelo.

Corte Constitucional colombiana. (10 de septiembre de 2013) Sentencia C-622. M.P. Mauricio González Cuervo.

Corte Constitucional colombiana. (19 de diciembre de 2013) Sentencia T-956. M.P. Luis Ernesto Vargas Silva.

Corte Constitucional colombiana. (7 de mayo de 2014) Sentencia T-278. M.S. Mauricio González Cuervo. 
Corte Constitucional colombiana. (3 de junio de 2015) Sentencia T-338. M.P. Jorge Iván Palacio Palacio.

Corte Constitucional colombiana. (16 de julio de 2015) Sentencia C-451. M.P. Jorge Iván Palacio Palacio.

Corte Constitucional colombiana. (20 de junio de 2016) Sentencia T-316. M.P. Luis Guillermo Guerrero Pérez.

Corte Constitucional colombiana. (30 de noviembre de 2017) Sentencia T-705. M.P. José Fernando Reyes Cuartas.

Corte Constitucional colombiana. ( $1^{\circ}$ de junio de 2018) Sentencia T-210. M.P. Gloria Stella Ortíz Delgado.

Corte Constitucional colombiana. (26 de junio de 2018) Sentencia T-241. M.P. Gloria Stella Ortíz Delgado.

Corte Constitucional colombiana. (24 de julio de 2018) Sentencia T-295. M.P. Gloria Stella Ortíz Delgado.

Corte Constitucional colombiana. (25 de febrero de 2019) Sentencia T-074. M.P. Antonio José Lizarazo Ocampo. 